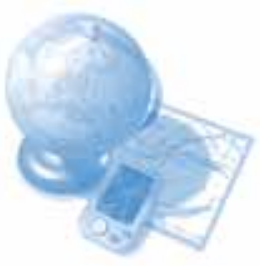

Derek Raine

TCETL

Department of Physics and

Astronomy

University of Leicester

Leicester

LE1 7RH

jdr@le.ac.uk

\section{Integrated Sciences}

\begin{abstract}
Science education seems to be diverging between an inclusive approach to general science and a contracting somewhat watered down discipline based approach. An inclusive but challenging curriculum should be based on real-world problems that are largely interdisciplinary. This will provide a virtuous circle of teachers enthusiastic about science communicating its relevance to their students.
\end{abstract}

\section{Introduction}

I would like to draw your attention to an interesting paradox. No-one in your Department knows more about your discipline than your newly graduating students. Of course, you are more of an expert on some aspect of your subject, but, unless you are very different from the academics I know, you would probably fail some of the options your undergraduates take in their stride, and in many cases some of the core too. Once they go on to research your students will also narrow their focus to the left eyebrow of the armadillo, on which subject they will give keynote addresses and enter vigorous e-mail dialogues with their fellow experts. Why do we insist that students start from a broader base than their teachers? The answer is so obvious l'll treat the question as rhetorical. But let me change the question a little. Why do we insist that the breadth of this base is so narrow? Why, when all the important issues facing the future of the human race are interdisciplinary, do we still engage in the discipline snobbery of an educational system that was designed primarily to produce the very best string theorists and quantum chemists?

While you are thinking that one out, I have a question from the opposite point of view: what do you think an anti-elitist approach to science education will do to recruitment of the best minds into science? Of course, we know the answer to this since it has already been the subject of a mass education experiment.

We appear to be caught in a classic pincer movement. On the one hand we desperately want science to be inclusive, not just for its own sake, but because we really need a scientifically literate community. And, on the other hand, we know that much of science cannot be simplified without it ceasing to be science, just as you can't leave out the left hand notes in a Mozart piano piece to make it simpler, without it ceasing to be music.

So what has emerged? We appear to be seeing the evolution of a two-tier system. On the one hand an approach based on the traditional disciplines of physics, chemistry and biology, somewhat watered down, but available, in the diminishing numbers of schools with specialist teachers, to just the few, most of who will opt in higher education for psychology, medicine and media studies rather than physics or chemistry. And, on the other hand, an imaginative Applied Science agenda offered, apparently, to those who can't do proper physics or chemistry and are not going to be scientists. I cannot believe that this is how the future was meant to be.

You may argue that another seven thousand brilliant physics and chemistry teachers will fix the problem. But, let's face it, that isn't going to happen, because the present curriculum is designed not to make it happen; nor should it, because the purpose of an educational system is not solely or even primarily to produce teachers.

To my mind the solution to a curriculum that is both inclusive and challenging is to start from the interesting scientific problems. It doesn't matter if these are discipline specific or interdisciplinary. It doesn't matter if these are problems of applied science and technology or purely intellectual puzzles. It does matter that they should be scientific issues, not sociology dressed in scientific clothing. It does matter that they are problems that can be tackled at several levels (not usually problematic in science). It does matter 
that they are problems, not solutions. The practice of science, as opposed to its reportage, is not about facts and answers, but about what can reasonably be said in the face of uncertain and incomplete information (something that it is very easy to replicate in the classroom).

\section{Integrated Sciences}

The IScience programme (see note) at Leicester which we started three years ago and has this year produced its first graduates, seeks to take this approach in higher education. Each specially written module in the programme is based on an interdisciplinary problem, requiring a detailed scientific investigation to offer a possible solution or response at various levels. Students are thereby taken to the frontiers of science across a range of areas in physics, chemistry, biology and earth sciences. This has now been taken up as a national programme, currently involving Surrey, the University of East Anglia and London South Bank University, under the banner of Integrated Sciences and under the leadership of the Institute of Physics, with HEFCE funding. This context has provided the imaginative missing link from the original Leicester programme: the option to transfer to the second or third year of a single discipline after 2 or 3 years of ISciences.

Some of the module descriptions will give a flavour of the

Leicester programme. In the first year Science of the Invisible

looks at chemical bonding, cell biology and the physical properties of solids, liquids and gases from a novel point of view, so that it is accessible and appealing to students with a variety of backgrounds which may include A-Levels in one or more of these disciplines. Furthermore, we do not aim for content coverage of all of the sciences, which would restrict the programme to a broad but basic level, but for a basis on which we can get to the research frontiers in a limited number of areas. Forensics is a second year module which requires students to act as expert witnesses in a murder mystery. (We get a law lecturer to play the role of judge in the final courtroom presentation assessment, with IScience staff crossexamining.) This is a good topic to include physics (time of death analysis from rates of cooling), chemistry (blood alcohol and drug analysis) and, of course, genetics. The Earth through Time in year 3 looks at many aspects of climate change. About this module one of our students comments:

"I particularly enjoyed the final module of my third year on climate change. We looked at specific geological events, then moved to the IT suite to understand how you model these very hot or cold events. This helped us gain an understanding of climate modelling and prediction, a subject that's in the headlines all the time. The module was a great example of combining text-book knowledge, practical experience and access to leading experts in the field.... When I left school I really wanted to get involved in cutting edge research and l've achieved my ambition. My career options are really open."

Thus we now have the model of an inclusive science programme that pays due respect both to the integrated nature of science and its discipline based specialist expertise. Rolling this backwards, we can see how a science programme in schools designed for the needs of the full range of student interests and abilities based on an interdisciplinary approach would provide the virtuous circle so absent from our current structures: a source of enthusiastic teachers with the morale to generate enthusiastic students. What seems to be lacking is simply the vision that science is not what you get when you dumb down physics and chemistry, but what all students, especially including the very best, should be engaged with as a preparation for a science-based world.

Note:

The original programme at Leicester was called Interdisciplinary Science and labelled i-Science for short. The national programme is called Integrated Sciences and referred to as ISciences. To develop

some sense of brand image, we are in the process of dropping the Leicester hyphen and calling our degree IScience for short. All combinations work for e-mails and our web site. 